\title{
OS SABERES PEDAGÓGICOS NA FORMAÇÃO DO PROFESSOR DE LÍNGUA PORTUGUESA
}

\author{
Elizia Graziele Oliveira Everton ${ }^{1}$ \\ Maria Núbia Barbosa Bonfim²
}

\section{RESUMO}

Neste estudo, analisa-se a formação pedagógica do Curso de Licenciatura em Letras da Universidade Federal do Maranhão, no campus do Bacanga, com sede em São Luís. A tessitura dessa pesquisa baseia-se na abordagem qualitativa, mais precisamente no estudo de caso. Fez-se uso da entrevista semiestruturada, enquanto instrumento metodológico, com alunos dos dois últimos períodos e professores das disciplinas pedagógicas. Como técnica de tratamento e análise de dados, fez-se uso da análise de conteúdo. As representações dos sujeitos da pesquisa apontam algumas fragilidades na formação pedagógica, mas com uma perspectiva de mudança, para que o Curso se fortaleça enquanto Licenciatura e para que a formação pedagógica ganhe um lugar de destaque.

Palavras-chave: Formação docente. Saberes pedagógicos. Formação pedagógica.

1 Pedagoga/Supervisora Escolar da rede de ensino do Estado do Maranhão. Mestre em Educação pela Universidade Federal do Maranhão. E-mail: elizia_graziele@hotmail.com.

2 Professora Permanente do Programa de Pós-Graduação em Educação da Universidade Federal do Maranhão-UFMA. Integra o Grupo de Pesquisa Escola, Currículo, Formação e Trabalho Docente.Doutora em Ciências da Educação pela Universidade de Coimbra. E-mail: bonfim@elo.com.br. 


\title{
THE PEDAGOGICAL KNOWLEDGE ON THE PORTUGUESE LANGUAGE TEACHER TRAINING
}

\begin{abstract}
In the study, we analyze the pedagogical training of the Letters Course at Federal University of Maranhão, Bacanga campus, based in "São Luís". The elaboration of this research on qualitative approach, is more precisely in the case studied. It was used semi-structured interview as a methodogical tool with students of the last two periods and teachers of educacional disciplines. As data processing and analysis technique, it was made content analysis. The representations of the research subjects showed some weaknesses in teacher training, but with a change of perspective so the course can be strengthened as a Formation and for pedagogical training earn a prominent place.
\end{abstract}

Keywords: Teacher training. Pedagogical knowledge. Pedagogical training.

\section{LOS SABERES PEDAGÓGICOS EN LA FORMACIÓN DEL MAESTRO DE LENGUA PORTUGUESA}

\section{RESUMEN}

En este estudio, se analiza la formación pedagógica del Curso de Licenciatura en Letras de la Universidad Federal do Maranhão, en el campus del Bacanga, con sede en São Luís. La tesitura de esa investigación se basa en el enfoque cualitativo, más exactamente en el estudio de caso. Se realizó una entrevista semiestructurada, mientras instrumento metodológico, con alumnos de los dos últimos períodos y profesores de las asignaturas pedagógicas. Como técnica de tratamiento y análisis de datos, se hizo uso del análisis de contenido. Las representaciones de los sujetos de la investigación apuntan algunas fragilidades en la formación 
pedagógica, pero con una perspectiva de cambio, para que el Curso se fortalezca como Licenciatura y para que la formación pedagógica gane un lugar de destaque.

Palabras clave: Formación docente. Saberes pedagógicos. Formación pedagógica.

\section{INTRODUÇÃO}

Este estudo apresenta o resultado de estudos desenvolvidos pelo grupo de Pesquisa Metodologia do Ensino da Língua Portuguesa - MELP, constituído pelo Projeto de Cooperação Acadêmica - PROCAD NF: Disciplinas das Licenciaturas voltadas para o ensino de Língua Portuguesa, apoiada pela coordenação de Aperfeiçoamento de Pessoal de Nível Superior - CAPES ${ }^{3}$.

O interesse pelo tema surgiu das diversas discussões acerca da relevância das disciplinas pedagógicas nos Cursos de Licenciaturas, pois entendemos que quando bem trabalhadas, ajudam na qualidade da prática docente e por consequência, na qualidade da educação básica.

A escolha pelo Curso de Licenciatura em Letras, com ênfase na formação do professor de Língua Portuguesa se deu por dois motivos principais: o primeiro metodológico, pois era metodologicamente impossível estudar todos os Cursos de Licenciatura. E o segundo, por convicção, pois acreditamos que um bom processo de ensino e aprendizagem na Língua Materna é condição indispensável para uma emancipação pessoal e profissional dos alunos da educação básica.

Assim, elaboramos o seguinte objetivo geral: analisar como se delineia a formação pedagógica do professor de Língua Portuguesa a partir dos saberes pedagógicos mobilizados nas disciplinas pedagógicas do Curso de Licenciatura em Letras de uma Universidade de São Luís.

3 Desse Projeto fizeram parte a Universidade de São Paulo - USP, a Universidade Estadual do Rio Grande do Norte - UERN e a Universidade Federal do Maranhão, na qualidade de instituição proponente. 
Para tanto, usamos os recursos da pesquisa qualitativa, que de acordo com Minayo (2007), se aprofundam no mundo dos significados, em um nível de realidade não visível que precisa ser exposta e interpretada. Dentre as várias formas que a pesquisa qualitativa pode assumir, optamos pelo estudo de caso, que segundo Lüdke e André (1986), se destaca por constituir uma unidade dentro de um contexto mais amplo.

Na referida pesquisa utilizamos a entrevista como principal instrumento de coleta de dados, uma vez que Gil (1998) a aponta como uma técnica muito eficiente para obtenção de dados em profundidade acerca do comportamento humano. Assim tivemos como sujeitos da pesquisa, 8 professores das disciplinas pedagógicas e 10 alunos concluintes do Curso de Licenciatura em Letras da Universidade Federal do Maranhão, lócus da pesquisa.

Para análise e interpretação dos dados da pesquisa utilizamos a técnica da análise de conteúdo, que nos permite fazer inferências que partem da descrição dos conteúdos existentes na comunicação, caminhando na descoberta do que está por trás dos conteúdos manifestos, indo além das aparências do que está sendo comunicado (GOMES, 2007).

Seguindo esse percurso metodológico, adotamos uma linha de análise crítica, pois esta procura um caminho para explicação do real considerando a multiplicidade da prática social, incluindo suas contradições; sendo então adequada para trabalhar a relação parte/ todo que se revela no estudo de caso.

Fundamentados em Giroux (1997), entendemos que essa análise requer uma forma de trabalho na qual pensamento e ação estão intrinsecamente relacionados e oferece uma contra ideologia para as pedagogias instrumentais e administrativas que separam concepção de execução e ignoram a especificidade das experiências e formas subjetivas que moldam o comportamento de estudantes e professores.

Nesse sentido, utilizamos o conceito de Tardif (2010, p. 36), para saberes docentes: "Pode-se definir o saber docente como um saber 
plural, formado pelo amálgama, mais ou menos coerente, de saberes oriundos, da formação profissional e de saberes disciplinares, curriculares e experienciais".

Como podemos perceber, a questão do saber ocupa um lugar estratégico na formação de professores que ainda, de acordo com o autor, intervém em pelo menos dois níveis da formação: sendo o fundamento da qualificação profissional e sendo a própria matéria do processo do trabalho educativo, uma vez que esse trabalho objetiva a transmissão e a aquisição de saberes por parte dos alunos.

Nesse sentido, os professores se apropriam de saberes que vão legitimá-los como profissionais, ao mesmo tempo em que esses saberes serão seu "material" de trabalho. A questão reside na maneira como esse professor vai lidar com esses saberes e como vai transmití-los aos seus alunos do ensino básico.

Com efeito, se advogamos a favor de uma concepção crítica de educação, advogamos também que as instituições formadoras ofereçam um conjunto de saberes pedagógicos que possam embasar uma prática de ensino correspondente a essa concepção de educação.

No entanto, entendemos que os saberes pedagógicos que correspondem a uma concepção crítica de educação devem dialogar com uma concepção de linguagem interacionista, que segundo Antunes (2003, p. 42), deriva do princípio geral de que “[...] a língua só se atualiza a serviço da comunicação intersubjetiva, em situações de atuação social e práticas discursivas, materializada em textos orais e escritos", e que este deve ser o ponto de referência quando se quer definir todas as opções pedagógicas, desde a escolha dos objetivos, do conteúdo, a escolha das atividades e sua avaliação.

Finalizando, deixamos claro que apesar de destacarmos, nesse estudo, a importância da formação de professores e dos saberes pedagógicos para uma educação básica de qualidade, entendemos que essa qualidade perpassa também por outros fatores externos às salas de aulas universitárias e aos Cursos de Licenciaturas. 
Nesse sentido, não temos a pretensão de apontar responsáveis ou julgar as ações do Curso de Letras, em questão; o que esperamos é que nosso esforço em discutir esse tema, desdobre-se em novas buscas e estudos, na tentativa de sempre melhorar os cursos de formação inicial de professores da educação básica.

\section{O Curso de Letras da UFMA: breve contextualização}

Em São Luís, no Maranhão, o primeiro Curso de Letras tem sua origem ligada à criação da Faculdade de Filosofia de São Luís, instituído em 1952, criado pelo Decreto 32.606, de 23 de abril de 1953, (DOU 28.04.53), e reconhecido pelo Decreto 39.663, de 28 de julho de 1956. Sua criação foi o resultado de um conjunto de esforços da Academia Maranhense de Letras, Fundação Paulo Ramos e Arquidiocese de São Luís.

A estrutura curricular do Curso foi constituída por um Currículo Mínimo normatizado pela Resolução S/No/62-CFE de 19.10.62, Parecer № 283/62-CFE. A seguir, foi constituído por Currículo Pleno, regulamentado pelas seguintes Resoluções: Resolução № 09/86-CONSUN, de 25.05.86; Resoluções n॰ 01/90, n 06 e, 07/93 e 09/94CONSUN.

Na Faculdade de Filosofia, Ciências e Letras, a princípio funcionavam as áreas de Línguas Neolatinas e Anglo-Germânicas, com Francês, Inglês, Espanhol, Latim e Português; sendo incluída, posteriormente, a Língua Italiana. O Curso oferecia duas habilitações: o Bacharelado (3 anos) e a Licenciatura ( 1 ano), adotando o esquema conhecido como" $3+1$ ".

De acordo com Bonfim (2007), mesmo com a criação da Fundação Universidade do Maranhão, dez anos depois - atual Universidade Federal do Maranhão, o Curso de Letras continuou vinculado à Faculdade de Filosofia, até 1970, quando é desmembrado e passa a fazer parte do Instituto de Letras e Artes - ILA, que com a Lei da Reforma Universitária, a Lei 5540/68, é desmembrado em dois 
Departamentos Acadêmicos: o de Estudos Luso-Brasileiros e o de Letras, Artes e Comunicações.

O Curso de Letras compreendia o Departamento de Estudos Luso-Brasileiro (DELB) e o Departamento de Letras (DEL), posteriormente DELER. Mais tarde, com a construção do Campus, no Bacanga e com a criação dos Centros, o Curso de Letras passou a integrar o Centro de Estudos Básicos, hoje Centro de Ciências Humanas.

Dentre as várias mudanças que foram ocorrendo ao longo dos anos no Curso de Letras, a considerada maior é a reformulação curricular aprovada pela Resolução no 09/86 - CONSUN, em 25 de maio de 1986, que extingue a oferta do Bacharelado, passando a oferecer apenas a Licenciatura em Letras.

A partir daí, o Curso passou a oferecer Licenciatura Plena com Habilitação em Língua Portuguesa e respectivas literaturas e uma Língua Estrangeira (Francês, Inglês, Espanhol e Alemão) com suas respectivas literaturas.

Com a proposta das Diretrizes Curriculares Nacionais para os Cursos de Letras, estabelecidas pela Resolução CNE/CES no 18/2002, tendo como fundamento o Parecer CNE/CES no 492/2001, que versa sobre as Diretrizes Curriculares Nacionais de vários cursos de graduação, dentre eles, o de Letras, retificado pelo Parecer CNE/CES n 1363/2001, foi elaborado, em 2005, o Projeto Político Pedagógico - PPP do Curso de Letras da UFMA, em que o Curso permanece organizado em habilitações e com a seguinte denominação: Curso de Letras com Habilitação em Língua Portuguesa, Língua Estrangeira e respectivas literaturas.

No entanto, em conformidade com o Parecer CNE/CES n ${ }^{\circ}$ 223/2006, que afirma que não pode haver habilitação nos Cursos de Letras, atualmente, essa habilitação foi desmembrada em três Cursos, são eles: Letras Português/Espanhol, Letras Português/Francês e Letras Português/Inglês; cada um com suas respectivas literaturas; passando a serem ofertados desde 2011. No entanto, já existe uma discussão sobre uma possível reinserção do Bacharelado. 
Atualmente, o Curso de Letras da UFMA (alvo do nosso estudo), funciona no Campus do Bacanga, no Centro de Ciências Humanas, no turno matutino. Possui no quadro docente de seu departamento, 35 professores efetivos, sendo: 14 professores doutores, 1 professora pós-doutora e 18 mestres, dos quais 07 estão em processo de doutoramento, além de 09 professores substitutos, sendo o seu Colegiado formado por 8 professores.

De acordo com sua Coordenação, em 2012 (semestre 2012.2), o Curso possuía um total de 346 alunos ativos, assim distribuídos: 168 alunos em Letras Português/Inglês, 122 alunos em Letras Português/ Espanhol e 56 alunos em Letras Português/Francês.

Segundo a Pró-Reitoria de Pesquisa e Extensão, o Departamento de Letras possui 07 Projetos de Pesquisa e 3 Projetos de Extensão, em andamento.

No Maranhão, o Curso de Letras é oferecido por 11 instituições ${ }^{4}$, sendo 7 Instituições atuando na modalidade Presencial, são elas: FAMA (atualmente pertencente a rede Pitágoras), FAP, CESSF, IESM, UNICEUMA, UEMA E UFMA; e 4 Instituições atuando na modalidade à Distância, dentre elas: UNINTER, ULBRA, UNIMES e UNOPAR ${ }^{5}$.

Formação pedagógica: os saberes pedagógicos do professor de Língua Portuguesa

$\mathrm{Na}$ análise do modelo de formação docente, vimos que o Curso de Letras da UFMA, assim como acontece com outros Cursos de Licenciatura pelo Brasil, é herdeiro de um modelo pautado nos pressupostos da racionalidade técnica, que percorreu toda a história da Educação brasileira.

4 Centro Universitário Internacional - UNINTER; Faculdade Atenas Maranhense - FAMA; Faculdade do Baixo Parnaíba - FAP; Faculdade Santa Fé - CESSF; Instituto de Ensino Superior Múltiplo - IESM; Universidade do Ceuma - UNICEUMA; Universidade Estadual do Maranhão - UEMA; Universidade Luterana do Brasil - ULBRA; Universidade Metropolitana de Santos UNIMES; Universidade Norte do Paraná - UNOPAR.

5 Dados extraídos do Ministério de Educação. Disponível em:<http://www.emec.mec.gov. br>. Acesso em: 18 nov. 2012. 
Mesmo com todas as reformas curriculares pelas quais o Curso vem passando ao longo dos anos, ele se consolidou nesse modelo, conhecido também como $3+1$, no qual o aluno cursava o bacharelado nos três primeiros anos e no último ano cursava a licenciatura.

Esse modelo trouxe uma série de consequências que até hoje são sentidas pelos alunos e pelos professores, quando colocam que o Curso não tem uma identidade de Licenciatura e que suas disciplinas formam o bacharel e não o professor, embora os professores das disciplinas pedagógicas, que pertencem ao Departamento de Letras, venham lutando para que o Curso entenda sua condição de Licenciatura.

Uma das ações implementadas, no sentido de diminuir essa sensação descrita por alunos e professores foi uma reformulação do Projeto Político Pedagógico do Curso, promovendo sessões de leitura do documento, debates sobre como poderiam construir as ementas das disciplinas com conteúdos mais voltados ao Ensino da Educação Básica. Mas essa reformulação aconteceu em 2010, portanto, os alunos entrevistados ainda não sentem seus efeitos e pela fala dos professores, esse novo PPP ainda não conseguiu se consolidar, pois quando fazem suas considerações, eles sempre se reportam ao currículo do PPP de 2006.

Baseando-se nesse currículo de 2006, os alunos colocam que são mais preparados para atuarem como redatores, críticos literários, críticos em linguística, e que na hora de dar aula eles saem com um déficit. Afirmam, por exemplo, que passam mais tempo discutindo a teoria linguística do que vendo maneiras de trabalhar a gramática nesse viés da linguística, distanciando a formação da Educação Básica, embora o Curso seja de Licenciatura.

Assim, a maioria dos alunos não se sente preparada para enfrentar a sala de aula levando em consideração o modelo oferecido pelo Curso. Opinião compartilhada pelos professores ao afirmarem que a formação apesar de ter melhorado ainda não é a ideal. Segundo a maioria dos alunos esse modelo de formação atual não atende às suas pretensões como futuros professores. 
No tocante aos saberes docentes, gostaríamos de perceber como os professores lidam com os saberes docentes, mais especificamente com o saberes específicos e os saberes pedagógicos, como esses saberes se relacionam no Curso em questão, pois entendemos que um adequado processo de formação de professores deve articular esses saberes em uma perspectiva igualmente relevante, que os distinguem, ao mesmo tempo em que os entrelaçam.

Neste sentido, na unidade em questão, identificamos uma certa fragmentação nos conteúdos abordados, não sendo perceptível uma integração entre eles, fenômeno relatado pelos alunos quando colocam que não há uma interdisciplinaridade, que o foco da aplicação do conteúdo apresenta-se descontextualizado; que os professores de Língua Portuguesa não dialogam com os saberes pedagógicos, pois o seu foco são os saberes específicos e que as ementas das disciplinas não trazem conteúdos voltados para o ensino na Educação Básica.

Os alunos colocam, ainda, que os professores das disciplinas específicas criticam as intervenções pedagógicas, o que dificulta ainda mais a integração dessas disciplinas, pois a maneira como o professor lida com os saberes pedagógicos tem inúmeras implicações na vida dos alunos em todos os níveis.

De acordo com Tardif (2010), o professor ideal é alguém que além do conhecimento de sua matéria, sua disciplina e seu programa, deve possuir certos conhecimentos relativos às ciências da educação e à pedagogia. Para ele, são essas múltiplas articulações entre a prática docente e esses saberes que fazem dos professores um grupo social e profissional, cuja existência depende, em grande parte, de sua capacidade de dominar, integrar e mobilizar tais saberes enquanto condições para sua prática.

Os alunos apontam que muitos professores não acreditam e não dão importância aos saberes pedagógicos, e quando há esse descrédito essa relação entre os saberes tem muita chance de não acontecer, pois em última instância os saberes que fazem parte da 
formação profissional dos professores dependem da universidade e de seu corpo de professores formadores.

O que nos chamou atenção no relato dos alunos sobre essa relação entre as disciplinas específicas e pedagógicas foi o caráter fragmentado dessa formação, deixando perceptível a falta de integração entre os conteúdos. Assim, as diversas atividades e contribuições das disciplinas e do trabalho dos professores acontecem apenas se acumulando por justaposição, não se somam por integração, por convergência (SEVERINO, 2011).

Entendemos também que falta um diálogo entre os professores das disciplinas pedagógicas com os outros professores, principalmente entre aqueles que não pertencem ao Departamento de Letras, relatados pelos próprios professores e pelos alunos, quando dizem que as disciplinas são repetitivas, pois seus assuntos se repetem quando deveriam ser aprofundados.

Essa falta de diálogo se reflete na interação desses professores com o Curso, pois a maior parte deles disseram que sua interação se resume em uma apresentação à coordenação no primeiro dia de aula para receber informações referentes ao desenvolvimento da disciplina.

Analisando essas questões, Anastasiou (2010 p. 67), aponta “[...] que pensar a disciplina isoladamente, como preocupação pessoal e individual, faz parte da nossa história profissional [...]" e que pensála coletivamente leva a outro tipo de trabalho, que exige uma abertura para a escuta do outro, tanto do professor que atua no mesmo semestre ou no semestre anterior, quanto para a escuta do aluno.

No que diz respeito à prioridade do Curso e dos alunos, a maioria dos sujeitos da pesquisa concorda que essa prioridade é dada aos saberes específicos. Essa prioridade também pode ser identificada na forma como são tratadas as disciplinas pedagógicas pelos alunos e pelo Curso, pois os professores relatam uma certa resistência dos alunos em relação às disciplinas que se refletem no pouco número de 
matriculados em algumas disciplinas.

Por sua vez, os alunos colocam que nem sempre essas disciplinas são oferecidas, porque faltam professores, mas concordam com os professores que a maioria dos alunos vai deixando as disciplinas pedagógicas de lado e só se matricula quando não tem mais jeito, pois eles só podem se matricular nos estágios depois que cursaram todas as disciplinas pedagógicas.

No que diz respeito a concepção de linguagem, um aspecto positivo é que todos os professores e alunos disseram que linguagem é interação, destacaram sua função comunicativa, a dinamicidade e variedade. Nesse contexto, identificamos nos professores uma preocupação em se desviar de aulas tradicionais, em que ele seria o centro do processo, para aulas mais interativas, onde a participação do aluno é importante.

Observamos que os alunos apreenderam essa concepção e sabem da importância de levá-la para suas aulas, eles falam sobre estimular a participação de seus alunos, mostrar a função social da Língua Portuguesa, valorizar as variedades linguísticas, de modo que cada uma tem sua importância dependendo do contexto em que é aplicada, dentre outras ações que essa concepção de linguagem comporta.

No entanto, os alunos têm dificuldades de operacionalizar os conceitos repassados, isso se reflete nos planos de aulas, que têm seus conteúdos voltados mais para a gramática normativa. De acordo com os alunos, as escolas exigem que o ensino de Língua Portuguesa esteja voltado para o ensino de gramática.

É relevante destacarmos que não somos contra o ensino de gramática, ao contrário, entendemos que esses conteúdos são exigidos pela sociedade, embora já exista um esforço em elaborar provas de concursos públicos com questões mais contextualizadas. $\mathrm{O}$ que defendemos é que esse ensino não esteja voltado exclusivamente para as questões gramaticais, que se tenha um ensino voltado também para as questões sociais da Língua. 
Assim, seria importante que esses licenciandos conseguissem levar essa concepção de linguagem para o ensino na Educação Básica, pois quase todos concordam que, em última instância, é na sala de aula que se materializam ou não os conteúdos e as estratégias de ensino-aprendizagem.

A dificuldade dos alunos em concretizar essa concepção de linguagem, pode estar no fato do Curso ser muito teórico, aliás, queixa recorrente entre os alunos, quando colocam que aprendem os conceitos, mas não como colocá-los em prática. Essa dificuldade é corroborada pelos professores ao apontarem que os alunos ainda chegam nos estágios com uma prática muito tradicional.

O desejo de formar profissionais cada vez mais cultos, informados e com uma sólida preparação científica, pedagógica e humanística passa necessariamente pelo processo pedagógico das salas de aulas universitárias (AQUINO; PUENTES, 2011). Assim, destacamos novamente a importância dos saberes pedagógicos na formação docente, desde saberes pedagógicos propriamente ditos até a maneira como eles são repassados aos alunos.

Nesse contexto, observamos que há uma certa insatisfação quanto às metodologias utilizadas pelos professores, dentre as quais as mais utilizadas são: textos, dinâmicas, discussões, vídeos (filmes), data show e slides, quadro branco. Dos alunos entrevistados, 2 estão satisfeitos, 4 estão em parte satisfeitos e 4 não consideram essas metodologias satisfatórias.

Dentre os motivos expostos pelos alunos que estão satisfeitos, está o fato de que os professores das disciplinas pedagógicas organizam melhor suas aulas e fazem os alunos produzirem.

Quantos aos alunos que estão em parte satisfeitos, os motivos mais elencados foram: a maneira como o professor administra essas disciplinas, falta de mais parte prática, limitação dos conteúdos apenas as teorias e aos pensamentos dos educadores. 
Dentre os motivos expostos pelos alunos que não estão satisfeitos com as metodologias utilizadas pelos professores, estão: a não relação da disciplina ou das teorias com a realidade, aulas tradicionais, divergência entre fala e ação do professor e conteúdos repetitivos.

É interessante ressaltar que os alunos não se colocam em relação à metodologia em si mesma, a satisfação deles está ligada ao tipo de uso que é feito dessas metodologias, isso nos leva a acreditar que não existe metodologia boa ou ruim, mas o uso que se faz dela vai dá significado ou não ao processo ensino-aprendizagem.

Os alunos dizem que para serem boas ou ruins vai depender da maneira como são utilizadas, destacamos, então, a importância do professor se preocupar com o uso que vai fazer das metodologias, uma vez que segundo Ghedin (2009), em geral os educadores vão ensinar da mesma forma que aprenderam na universidade.

Nesse aspecto, os professores universitários devem estar atentos ao que falam e ao que fazem, pois alguns alunos destacaram a divergência entre o discurso e a ação, então não adianta ter discursos críticos e emancipatórios sobre como deve ser o ensino e agir de outra forma, isso leva a um descrédito da disciplina e dos ensinamentos.

Acreditamos que para ser feito um bom uso das metodologias, "[...] é essencial delinear com precisão qual a concepção que se tem do processo pedagógico [...]" (AQUINO; PUENTES, 2011, p. 41). Uma visão difusa desse processo não permite que o professor projete de maneira consciente sua atividade profissional, entretanto, o conhecimento transparente sobre como trabalhar com o planejamento, a execução e o controle do processo pedagógico é essencial e central para atuação profissional.

Dentre as metodologias mais utilizadas pelos professores das disciplinas pedagógicas, estão: aula expositiva, aula expositiva dialogada, metodologia participativa, mesas redondas, seminários, estudo dirigido dos textos, data show e slides. 
Pelos seus relatos podemos inferir que eles já têm uma consciência de que a metodologia tradicional, cuja operação principal é a transmissão ancorada na memorização dos conteúdos, não é mais suficiente para dar conta do tipo de profissional e do tipo de ensino que a realidade atual requer. Identificamos uma preocupação com as metodologias utilizadas, pois afirmam que tentam diversificá-las para que os alunos vejam a importância de dinamizar as aulas.

Essa preocupação com os saberes pedagógicos é muito válida porque até bem pouco tempo, esses saberes não tinham espaço constituído na universidade e só tardiamente alcançaram certa legitimação, porque em geral o foco principal da pedagogia sempre foi a criança. Nesse sentido, os professores universitários costumam contar com a maturidade de seus alunos para responder às exigências desse nível de ensino.

Segundo Cunha (2009), isso se deve ao fato de que a docência universitária recebeu forte influência da concepção epistemológica moderna, própria da ciência moderna, presidida pela racionalidade técnica, em que o conhecimento específico assumia um valor significativamente maior do que o conhecimento pedagógico e das humanidades na formação do professores.

Essa maior atenção aos saberes pedagógicos por parte dos docentes se reflete na participação dos alunos, visto que todos os professores apontaram que os alunos são bem participativos nas suas aulas, embora cheguem com uma certa resistência em relação à disciplina. Informação confirmada pelos alunos, que se colocaram como alunos participativos e interessados nas questões pedagógicas, no entanto, condicionam essa participação à maneira como o professor conduz as aulas.

Essa participação por parte do aluno é algo essencial no processo ensino-aprendizagem, pois ao aluno cabe uma atuação ativa na construção e apropriação do conhecimento, isso permite a ele, orientar-se melhor em cada situação, bem como valorizar, reflexionar, 
gerar estratégias de aprendizagem e alcançar conclusões por si mesmos (AQUINO; PUENTES, 2011).

Chegamos, assim, a um ponto bem interessante, quando os alunos dizem participarem das aulas, informação confirmada pelos professores, mas ainda sim, a maioria dos alunos pesquisados está insatisfeita com a formação pedagógica recebida, com recorrentes reclamações sobre as disciplinas pedagógicas que segundo os alunos se detêm a mostrar apenas a teoria e que isso as tornam distantes da realidade que os formandos irão encontrar ou já encontraram em seus estágios.

Entendemos que as disciplinas pedagógicas, no Curso de Licenciatura analisado, primam mais pelo saber do que pelo fazer, quando no nosso entendimento poderia haver um equilíbrio entre esses conteúdos, nesse sentido, os alunos colocam que elas são muito teóricas e que o saber fazer não fica tão bem demarcado.

Essa realidade pode estar ligada a uma hierarquia dos conhecimentos, nesse sentido, seria interessante uma reorganização teoria/prática, pois nessa relação a teoria sempre precede a prática e a ela caberia o papel central na explicação frente ao mundo.

A relação teoria/prática traz consequências ao pensar pedagógico, especialmente no campo curricular, onde se criou e passou a desenvolver um modelo e uma realidade nos quais a "construção" do conhecimento se dá de forma linear e hierarquizada, com uma antecedência claramente estabelecida das disciplinas teóricas sobre as disciplinas práticas (ALVES, 2004).

Em que pese as mudanças positivas, importantes e significativas do Curso em superar o modelo da racionalidade técnica, o seu currículo anterior, no qual esses alunos estão sendo formados, apresenta essa relação, quando divide as disciplinas pedagógicas entre disciplinas teóricas (Didática I e II, Psicologia I e II, Informática aplicada à Educação e Organização da Educação Brasileira) e as práticas pedagógicas (Diagnóstico da Comunidade Escolar, Organização do 
Trabalho Pedagógico, Aproximação com a Prática, Intervenção da Realidade Escolar), que acontece em escolas da Educação Básica.

No currículo novo, essa divisão também aparece, com a diferença de que nele as disciplinas de Didática I e II, foram condensadas em Didática e Psicologia I e II foram condensadas em Psicologia da Educação.

É importante esclarecer que não advogamos a favor de um modelo que desvaloriza a teoria na formação de professores, pois a nosso ver é pouco provável que haja uma prática eficiente sem que ela esteja fundamentada em princípios teóricos sólidos.

Não se trata de inverter o estado atual de muita teoria e pouca prática, para muita prática e pouca teoria e com isso eliminar a formação teórica e política do profissional convertendo-o em um "prático" (FREITAS, 2011); assim a questão não está na quantidade de disciplinas teóricas ou práticas.

O cerne da questão está na forma como essas disciplinas se relacionam, nesse sentido, advogamos a favor da relação prática/ teoria/prática, na qual a prática social é condição para problematização do conhecimento que os estudantes precisam produzir e essa relação requer uma intervenção refletida da teoria, fundamentada numa visão interdisciplinar.

Se a prática social é importante nessa relação, então consideramos essencial que o ensino ultrapasse os limites da sala de aula, em que os alunos possam participar de projetos de pesquisa, projetos de extensão e eventos científicos.

Sobre a participação em projetos de pesquisa 1 aluno já participou e 5 alunos nunca participaram e dentre os motivos mais comentados, estão: não conseguiram conciliar os seus horários com os horários das reuniões e porque se vincularam à projetos de extensão muito cedo. 
Dos 4 alunos que participam de algum projeto de pesquisa: os motivos mais comentados foram: porque começou a fazer o trabalho de conclusão de curso na área do projeto, porque só a sala de aula não era suficiente e porque participar de um projeto de pesquisa dá mais chance de entrar em um mestrado, sendo este último motivo comum em todas as respostas.

Nesse caso, observamos um interesse em seguir uma carreira acadêmica e seguir a docência no Ensino Superior, todavia acreditamos que a pesquisa também é importante para aqueles que estão e os que irão trabalhar na Educação Básica, como argumenta Ghedin (2006, p. 230):

A defesa da pesquisa no processo de formação de professores é para dizer, antes de tudo, que o professor deve dominar os instrumentos técnicos para produção do conhecimento, para que seja um cientista da escola e não um mero operador de metodologias.

Assim, os licenciandos quebram essa relação de exterioridade que têm com os saberes, que Tardif (2010) aponta como uma relação de alienação entre os professores e os saberes, em que estes são vistos como técnicos que aplicam o conhecimento produzido por outros.

A pesquisa e a postura investigativa são fundamentais em Cursos de Licenciaturas que visem formar professores para atuarem como intelectuais transformadores, isso significa uma formação que supere a visão instrumental da profissão.

Quanto a participação em projetos de extensão, dos 10 alunos, 1 aluno já participou, 3 não participam e dentre os motivos estão falta de tempo, falta de interesse e porque já estão vinculados em projetos de pesquisa.

Dos 6 alunos que participam, 1 participa dando aula de 
Inglês, porque se identifica com a área e 5 participam do PIBID (Programa Institucional de Bolsas e Iniciação à Docência), dentre os motivos mais citados para participarem do PIBID, estão: o incentivo financeiro e a experiência que proporcionada pelo programa, já que eles mantêm um contato com a sala de aula e a realidade escolar.

Esses projetos mostram-se válidos porque colocam o aluno em contato com a realidade escolar muito cedo, dando a eles a oportunidade de estarem inseridos em sala de aula, vendo o contexto em que vão estar inseridos e ajudando-os a refletir se é essa profissão que querem seguir.

Quanto à participação em eventos científicos, 2 alunos participaram mais como monitores, 2 como ouvintes, 3 alunos como apresentadores, destacando o projeto de pesquisa como essencial no processo de produção e divulgação do conhecimento, e 3 alunos disseram que há um equilíbrio entre a participação como apresentadores e ouvintes.

Embora todos os alunos entrevistados participem de projeto de extensão ou de pesquisa, ou já tenham participado de algum dos dois, isso não foi condição para que eles tivessem maior facilidade para falar dos saberes pedagógicos adquiridos no Curso de Letras.

Quando perguntamos se podiam identificar pelo menos 4 saberes pedagógicos que consideram fundamentais para sua prática docente e que foram adquiridos durante o Curso, tiveram muitas dificuldades e tivemos que dar exemplos de saberes pedagógicos e ainda sim, tiveram dificuldade em falar deles.

Sendo que 3 alunos não souberam identificá-los, pelos seguintes motivos: não foram repassados pelo Curso; não conseguiram identificá-los pelas disciplinas pedagógicas que tiveram e um respondeu que seus saberes não foram repassados pelo Curso, mas adquiridos pela experiência.

Dentre os saberes apresentados estão: saber planejar 
(mas esse planejamento é mais teórico); conhecer o ambiente em que vai trabalhar, conhecer o PPP da escola; diagnosticar os alunos com quem vai trabalhar; saber questionar e saber ouvir; ter uma postura firma, mas sem autoritarismo; ter uma visão positiva das coisas; ser crítico; estabelecer uma interação professor - aluno; dar importância à afetividade na relação ensino-aprendizagem; ter uma concepção sobre Escola; ter uma concepção sobre ser Professor; dar importância às metodologias; possuir conhecimento sobre aprendizagem dos alunos.

É interessante observar que os alunos enumeram saberes que não têm só a ver com o saber fazer, mas que têm a ver com uma posição político-ideológico do que é ser professor, nesse sentido, eles apontam muito sobre a importância de ter esses conhecimentos, e para nós ter essa consciência já é muito importante, apesar de que não apontam como colocá-los em prática.

No entanto, esse refletir sobre os saberes é importante, no sentido de que os saberes pedagógicos apresentam-se como doutrinas ou concepções provenientes de reflexões sobre a prática educativa e são essas concepções que incorporadas à formação do professor fornecem além de um arcabouço ideológico à profissão, algumas formas de saberfazer e algumas técnicas (TARDIF, 2010).

Entendemos que os alunos apresentaram um conjunto de saberes muito interessante do ponto vista teórico-ideológico, que são importantes e devem fornecer um arcabouço ideológico, além de algumas formas de saber fazer e algumas técnicas.

Todavia, de acordo com os dados coletados, acreditamos que no Curso de Letras, está faltando um pouco mais de conteúdos procedimentais, "[...] que inclui, entre outras coisas as regras, as técnicas, os métodos, as destrezas ou habilidades, as estratégias ou procedimentos" (ZABALA, 1998, p. 43). E a realização das ações que compõem o procedimento é o seu ponto de partida.

Essas ações não deveriam ser deixadas para o final do Curso, somente para o momento do Estágio, sendo essa outra insatisfação dos 
alunos, ao apontarem que só colocam em prática esses ensinamentos no momento do Estágio e que este só acontece no final do Curso, portanto se eles deixaram de aprender alguma coisa, não tem mais como voltar atrás.

Além disso, para alguns alunos que nunca trabalharam na área, o momento do Estágio é o primeiro contato com a regência em sala de aula e por ele ser final, esses alunos entram em contato com essa realidade tardiamente, desencadeando uma série de dificuldades na regência da aula, que por vezes acabam frustrando o futuro profissional.

Todas essas questões influenciaram a visão dos alunos sobre a formação pedagógica do Curso de Letras, pois dentre os 10 alunos entrevistados, só 1 respondeu ser boa, 3 disseram ser razoável e para 6 não é boa, sendo pobre, frágil e deixando a desejar.

estão:

Dentre os motivos mais citados para essa insatisfação,

a) Não são preparados para lidar com os problemas da sala de aula, nem para ministrar uma aula de português;

b) Não saem preparados para a realidade que encontram na escola;

c) Falta foco nessas disciplinas por parte dos Cursos;

d) A atuação em sala de aula é feita só no final do Curso, no Estágio;

e) Faltam professores e/ou estão entrando professores sem afinco com a área;

f) Não tem professores de Letras para ministrar essas disciplinas.

No que diz respeito à visão dos professores sobre a formação pedagógica do Curso, as respostas foram as mais variadas 
possíveis, mas a maioria posicionou-se positivamente. Vejamos:

a) 2 professores não tiveram elementos para responder, porque não conhecem o currículo do Curso;

b) 1 disse ser positiva, porque percebe os alunos bem fundamentados;

c) 1 percebe que condiz com o que é ofertado;

d) 1 entende que pode melhorar, porque os alunos ainda não tem consciência dessa formação;

e) 1 disse que evoluiu muito;

f) 1 falou que é interessante, pelo menos na proposta;

g) 1 colocou que pela carga horária e pelos os conteúdos, é muito boa.

Os alunos e professores tiveram a chance de refletir sobre os pontos positivos e negativos da formação pedagógica do Curso de Letras, sendo, pois, legítimo que eles pudessem sugerir ações tendo em vista a melhoria dessa formação.

As sugestões dos alunos foram que:

a) OCurso precisa sensibilizar os alunos desde seu ingresso de estão em um Curso de Licenciatura, portanto, serão professores;

b) O Curso sensibilize os alunos para a importância das disciplinas pedagógicas;

c) Exista um diálogo entre os professores das disciplinas pedagógicas e das específicas;

d) O Curso proporcione uma vivência do aluno na escola de 
Educação Básica desde o seu ingresso na Licenciatura6;

e) O próprio Departamento de Letras ofereça professores para ministrar as disciplinas pedagógicas, pois sendo concursados para dar aula exclusivamente em Letras, os professores teriam uma vivência maior no Curso;

f) Os professores das disciplinas específicas realizem estudos sobre os saberes pedagógicos, porque alguns não percebem a importância desses conhecimentos;

g) Fosse diminuída a quantidade de disciplinas que são repetitivas a fim de trabalhá-las melhor?;

h) As atividades sejam executadas nas escolas de Educação Básica;

i) As metodologias das disciplinas pedagógicas passem por um aprimoramento;

j) O Curso ensine a trabalhar com crianças.

Dentre as sugestões dos professores, estão:

a) Que os professores do Departamento de Letras lessem o seu PPP, de modo que se conscientizassem sobre o Curso que é de Licenciatura e voltado para a formação de professores para a Educação Básica e não para o Ensino Superior;

b) Que os professores das disciplinas específicas fizessem uma relação com os saberes pedagógicos, mostrando aos seus alunos como trabalhar com determinados

6 Entendemos que pela estrutura curricular o Curso já proporciona essa vivência, pois as práticas pedagógicas estão previstas desde o $3^{\circ}$ período, então a questão pode estar na maneira como estão sendo desenvolvidas essas disciplinas e se estão sendo ofertadas no período que o currículo prevê.

7 Essa reivindicação foi atendida na reformulação do PPP do Curso, onde houve uma redução no número de disciplinas específicas, vale lembrar que, esses alunos fazem parte do currículo antigo, o que está inserido no PPP de 2006. 
conteúdos;

c) Que houvesse mais professores para trabalhar com as práticas pedagógicas, porque o Curso não tem esse quadro formado, então, falta material humano, um reforço técnico para trabalhar essa formação pedagógica dentro do Curso;

d) Que o Curso sensibilizasse o aluno sobre o que é ser professor e qual a importância desse trabalho para os alunos da Educação Básica;

e) Que os alunos lessem mais os clássicos, que parassem de ater só aos manuais;

f) Que os alunos não viessem obrigados a fazer uma disciplina só porque esta faz parte da estrutura curricular;

g) Que houvesse uma discussão no âmbito do Departamento de Educação no sentido de realizar debates sobre as Diretrizes e o PPP dos outros Cursos e de discutir entre os professores como poderiam trabalhar melhor nas Licenciaturas;

h) Que o Curso de Letras repensasse formas para fortalecer essa formação pedagógica.

Podemos perceber que as sugestões dos alunos estão mais ligadas às aulas, propriamente ditas, das disciplinas pedagógicas, a maneira como os professores trabalham, suas metodologias e conteúdos. Já as sugestões dos professores estão mais ligadas às questões administrativas dos Departamentos e de como eles podem desenvolver ações para fortalecer a formação pedagógica.

Dessa forma, segundo o estudo que realizamos, esses são alguns aspectos que traçam a formação pedagógica do Curso de Letras pesquisado, construídos a partir da visão dos atores sociais e da 
sua vivência, que por sua vez, nos permite inferir que, apesar de todos os esforços empreendidos, a formação pedagógica ainda tem algumas fragilidades que comprometem sua efetividade.

\section{Considerações finais}

Acreditamos que a formação pedagógica é um importante elemento na formação docente que influencia diretamente o desempenho profissional em sala de aula, como a maneira que o professor se comporta, escolhe e didatiza os conteúdos, planeja, planeja, se relaciona com os alunos, entre outros aspectos que compõem a sala de aula.

Foi essa convicção que nos motivou a estudar a formação pedagógica do professor de Língua Portuguesa do Curso de Licenciatura em Letras, tendo sempre muito claro que a despeito dos resultados encontrados não podemos colocar somente na formação e na atuação do professor a culpa e a solução dos problemas educacionais que afligem a educação brasileira em todos os níveis.

Entendemos que a origem desses problemas é bem profunda e se encontra numa relação social mais ampla, portanto, não deve ser vista de forma mecânica e ingênua. Nesse sentido, a nossa intenção nunca foi de emitir um juízo de valor, mas trazer à tona questões que nos façam pensar em como podemos melhorar, sempre tentando fugir de modelos que incitem fórmulas a serem aplicadas para solução dos problemas.

Finalmente, cabe dizer que todos os aspectos estudados e analisados, tanto os de natureza teórica quanto os de natureza empírica, constituíram uma unidade, que nos permitiu descrever, analisar e compreender a formação pedagógica do Curso de Letras da UFMA. Sendo assim, podemos concluir que o Curso ainda não possui uma identidade de Licenciatura bem delimitada, o que desencadeia uma série de ações que atingem diretamente a formação pedagógica e os saberes mobilizados nessa formação. 
Entretanto, percebemos também uma perspectiva de mudança, alicerçada nos questionamentos dos estudantes e na luta diária dos professores das disciplinas pedagógicas que pertencem ao Departamento de Letras, para que o Curso se fortaleça enquanto Licenciatura e que a formação pedagógica ganhe lugar de destaque.

\section{Referências}

ALVES, N. Tecer conhecimento em rede. In: ALVES, N.; GARCIA, R. L. $\mathbf{O}$ Sentido da escola. Rio de Janeiro: DP\&A, 2004.

ANASTASIOU, L. das G. C. Ensinar, aprender, apreender e processos de ensinagem. In: ANASTASIOU, L. das G. C.; ALVES, L. P. (Orgs.). Processos de Ensinagem na Universidade: pressupostos para estratégias de trabalho em aula. 9. ed. Joinville: Univille, 2010.

ANTUNES, I. Aula de português: encontro e interação. São Paulo: Parábola Editorial, 2003.

AQUINO, O. F.; PUENTES, R. V. Trabalho didático na universidade: estratégias de formação. Campinas: Editora Alínea, 2011.

BONFIM, M. N. B. Na contramão do currículo: invertendo-se os caminhos de análise. 2007. 371 f. Dissertação. (Doutorado em Ciências da Educação) - Universidade de Coimbra, Coimbra: 2007.

CUNHA, M. I. Inovações Pedagógicas: o desafio da reconfiguração de saberes na docência universitária. In: PIMENTA, S. G.; ALMEIDA, M. I. (Orgs.). Pedagogia universitária. São Paulo: Editora da Universidade de São Paulo, 2009.

FREITAS, L. C. O Neotecnicismo e a Formação do Educador. In: ALVES, N. (Org.). Formação de professores: pensar e fazer. 11. ed. São Paulo: Cortez, 2011.

GHEDIN, E. A Articulação Estágio-Pesquisa na Formação do ProfessorPesquisador e seus Fundamentos. In: BARBOSA, R. L. L. (Org.). Formação de educadores: artes e técnicas: ciências e políticas. São Paulo: Editora UNESP, 2006.

Tendências e dimensões da formação do professor na 
contemporaneidade. Londrina: Universidade Estadual de Londrina, 2009.

GIL, A. C. Métodos e técnicas de pesquisa social. 4. ed. São Paulo: Atlas, 1998.

GIROUX, H. A. Os professores como intelectuais: rumo a uma pedagogia crítica da aprendizagem. Porto Alegre: Artmed Editora, 1997.

GOMES, R. Análise e Interpretação de Dados de Pesquisa Qualitativa. In: MINAYO, M. C. de S.; DESLANDES, S. F.; GOMES, R. (Orgs.). Pesquisa social: teoria, método e criatividade. 26. ed. Petrópolis: Vozes, 2007.

LÜDKE, M.; ANDRÉ, M. Pesquisas em educação: abordagens qualitativas. São Paulo: EDU, 1986.

MINAYO, M. C. de S. O desafio da pesquisa social. In: MINAYO, M. C. de S., DESLANDES, S. F.; GOMES, R. (Orgs.). Pesquisa social: teoria, método e criatividade. 26 ed. Petrópolis: Vozes, 2007.

SEVERINO, A. J. O conhecimento pedagógico e a interdisciplinaridade: o saber como intencionalização da prática. In: FAZENDA, I. Didática e interdisciplinaridade. 17 ed. Campinas: Papirus, 2011.

TARDIF, M. Saberes docentes e formação profissional. 11. ed. Petrópolis: Vozes, 2010.

ZABALA, A. A prática educativa: como ensinar. Tradução de Ernani F. da F. Silva. Porto Alegre: Artmed, 1998. 